\title{
EFFECTIVENESS OF MULTIMODAL PREEMPTIVE ANALGESIC THERAPY IN MAXILLOFACIAL SURGERY
}

\author{
SHOHDA KHATUN ${ }^{1}$, MOTIUR RAHMAN MOLLA ${ }^{1}$, A K M AKHTERUZZAMAN $^{2}$, MD SAYEDUR RAHMAN ${ }^{3}$
}

${ }^{1}$ Department of Oral \& Maxillofacial Surgery, ${ }^{2}$ Department of Anesthesiology, ${ }^{3}$ Department of Pharmacology, Bangabandhu Sheikh Mujib Medical University, Shahbag, Dhaka, Bangladesh

\begin{abstract}
This study was an attempt to find out the efficacy of pre-emptive analgesia in reducing post-operative pain. Multiple pre-emptive therapies were used in an attempt to see its superiority over single preemption. Pain scores showed significant differences between the pre-emptive and non pre-emptive groups. Pethidine consumed by the pre-emptive non-recipient group was much higher. Patient's satisfaction was higher and post operative complications were less in the pre-emptive recipient group. Thus pre-emptive multimodal therapy would be better, in reducing post-operative pain, and the amount of post-operative analgesic requirement. It might be concluded that multimodal preemptive therapy by using I/V Ketorolac \& Bupivacaine infiltration is an effective method for post operative pain management in maxillofacial surgery.
\end{abstract}

(Bangladesh J Physiol Pharmacol 2008; 24(1\&2) : 17-23)

\section{INTRODUCTION}

Effective pain management is essential for the patient during their recovery. Post- operative pain is basically an acute pain which is typically associated with neuroendocrine stress response that is proportional to the intensity of pain ${ }^{1}$. In addition to humanitarian reason for improving acute pain treatment, there is now convincing evidence that unrelieved postoperative pain may result in harmful physiological and psychological effects. These adverse effects may result in significant morbidity and even mortality ${ }^{2-5}$. The stress response to surgery and postoperative pain comprises a number of hormonal changes initiated by neural activation of the hypothalamic-pituitary-adrenal axis. In general the magnitude and duration of the response are proportional to the surgical injury and the development of complication ${ }^{1,6}$. This is also an important factor that influences recovery from major surgery and ability of the patient to return home and resume work. Postoperative pain management is also essential for the prevention of pulmonary complication and thromboembolic phenomena. Evidence of shortened hospital stay, increased patient satisfaction have been reported in association with effective relief of postoperative pain ${ }^{7-8}$.

Pain management is usually difficult as the response to pain varies between individual as well as in the same individuals in different occasions ${ }^{1}$. Unfortunately the patient's worries and fears of pain are

Address of Correspondence: Dr. Shohda Khatun, Department of Oral \& Maxillofacial Surgery, Bangabandhu Sheikh Mujib Medical University, Shahbag, Dhaka, Bangladesh low on the priority list of the medical personals. One of the frequently mentioned reasons of inadequate postoperative pain relief is the fear of the surgeon and nurses regarding administration of appropriate analgesics in response to fear of adverse effects of medicine.

Amongst the different methods, regional analgesia with local anesthetics and high dose of morphine/ Fentanyl inhibits the stress response to surgery and pain ${ }^{6}$, 9,10 . However that requires skilled manpower and can not be applied without side effects. Now a day, another combined analgesic method, opioid with NSAIDs is used to manage postoperative pain but the effect of this therapy on stress response is yet to be established ${ }^{11}$.

As discussed above, continuous research is going on to find better analgesic technique with the aim of reducing dose of opioid. For this reason, opioids are combined with NSAIDs on different occasions. The opioid sparing effect of nonsteroidal anti-inflammatory drugs has been reported ${ }^{12}$ and that can be used to reduce the dose and side effects of opioids. In most of the studies of these combined analgesic techniques, opoid was used by PCA or intramuscular fixed dose is given on demand or intrathecaly ${ }^{13,14,15}$. These studies show $40 \%$ to $60 \%$ reduction of opioid doses.

This study was conducted to assess the status of combined analgesic techniques with pre-emptive intravenous dose of Ketorolac and infiltration of Bupivacaine around the incision line as a measure to control postoperative pain. Post operatively pain was assessed by the Pethidine consumption used as a small 
intravenous dose intermittently with the help of patient control analgesia (PCA).

\section{Pain Measurement}

Pain is a personal subjective experience influenced by cultural learning, the meaning of the situation, attention and other psychological variable. Approaches to the measurement of pain includes verbal and number selfrating scale, (VAS, MPQ) behavioral observation scale and physiological responses.

\section{Rating Scales}

Until recently the methods those were used for pain measurement treated pain as that varies only in intensity. These methods include, verbal rating scale (e.g. mild, moderate, severe) numerical rating scale (1-100) and Visual Analogue Scale ${ }^{16}$. These simple methods have all been used effectively in hospital and clinics, and haveprovided valuable information about pain and analgesia. The most common VAS consists of a $10 \mathrm{~cm}$ horizontal or vertical line with the two endpoints labeled "No pain and worst pain ever"17,18.

The McGILL Pain Questionnaire (MPQ) is designed to assess the multidimensional nature of pain experience and has been demonstrated to be a reliable, valid and consistent measurement tool. But MPQ is more important on chronic pain measurement than acute postoperative pain. There was continues modification of MPQ pain measurement ${ }^{19,20,21}$.

\section{Pre-emptive Pain Management}

It is evident that the process involved in the human pain experience is complex. Theoretically, preventing or minimizing the afferent pain sensation, would reduce patient suffering and make post-operative pain management easier. However pre-emptive pain management, employing a single pre or intra-operative treatment to block the initial stimulus may be sufficient to have a lasting effect. It is probable that pain fiber should be continuously pre-empted, for as long as the afferent fiber of pain sensation continues to CNS. It is also likely that bi modal pain therapies are effective.

\section{Combined Analgesic Techniques}

The above mentioned drug therapy or techniques are not always individually effective without side effect. In an effort to improve pain control and decrease the incidence and severity of drug induced adverse side effects, many clinicians introduced the use of combined analgesic techniques. Different combined analgesic techniques are used for improving post operative pain. But all combined methods are not equally effective or always applicable without side effect or required special monitoring.

\section{Opioids with NSAIDS}

Recently, for severe post-operative pain, NSAIDs with Opioid are increasingly used. Many studies suggest that this combination reduced Opioid requirement with improved analgesia. Before 1990 there was very few studies about combined analgesia with opioid and NSAIDs. Afterwards, a number of studies have demonstrated the effectiveness of different NSAIDS in combination with opioids in different routes ${ }^{13}, 22,23,24,25$.

Ketorolac is a potent non-steroidal anti inflammatory drug whose action, efficacy and adverse effects are similar to other NSAIDs, but the non-irritant parental formulation has established a prominent role in the management of post operative pain. Ketorolac has a higher potency than most other NSAIDs. It is effective for moderate to severe pain. Though expensive than other NSAIDs it is useful where opioids are contraindicated, especially to avoid respiratory depression and sedation. It is often used as an adjunct to opioids ${ }^{26}$.

Infiltrating the incision site with local anesthetic Bupivacaine after administering general anesthesia and before incision was found to be more effective than either spinal anesthesia or general anesthesia alone and these benefits appeared to last many days ${ }^{27}$.

\section{MATERIALS AND METHODS}

Study duration: January 2005 to December 2006.

Place of the study: Department of Oral \& Maxillofacial Surgery, Bangabandhu Sheikh Mujib Medical University and Dhaka Dental College \& Hospital.

\section{Study design: Prospective Case Control Study.}

Inclusion Criteria: All patients of Oral \& Maxillofacial Surgery Department having ASA grade- I and II operation, patients agreed to give consent for this study and patient who can understand as well as use PCA.

All patients received conventional general anesthesia with pre-oxygenation for min with $100 \% \mathrm{O}_{2}$, then TPS- 3-5 mg/kg I/V and after suxamethonium 1-2 $\mathrm{mg} / \mathrm{kg}$ intubated and maintained with $\mathrm{N}_{2} \mathrm{O}: \mathrm{O}_{2}$ Halothane $66 \%, 33 \%$ \& $0.5 \%$. No opioids were used before or during operation and patients reversed at the end of operation with Neostigmine/Atropine.

In the post operative period patients were put on to intravenous PCA immediately. A loading dose of Pethidine $\mathrm{HCl} 30 \mathrm{mg}$ was given. PCA dose adjusted to $10 \mathrm{mg}$ with lock-out interval 20 min. Patients were assessed at 2, 4, $8,12 \& 24$ hours (time of incision is considered as ' 0 ' hour). 


\section{Patient Control Analgesia Device}

A PCA device consists of an electronic infusion pump that allows the patient to self- administers an analgesic medication. When the patient experiences pain, he or she pushes a button attached by a cord to the instrument. It then delivers a preset dose (interval dose) of medication via an indwelling intravenous catheter. The machine has a programmable period of time (Lockout time) after each interval dose administration during which it will not deliver dose even when activated by the patient. This lockout time is intended to prevent the patient from receiving an additional dose of the analgesic before the maximum effect of the previous dose is attained, thus decreasing the possibility of over medication.

\section{RESULTS}

Table I

Demographic Profile of the patients at the beginning of the study

\begin{tabular}{lccccc}
\hline & $\begin{array}{c}\text { Group I } \\
\text { Mean } \pm \text { SE }\end{array}$ & $\begin{array}{c}\text { Group II } \\
\text { Mean } \pm \text { SE }\end{array}$ & Mean \pm SE & Mean \pm SE & P value \\
\hline Age & $42.0 \pm 3.0$ & $34.8 \pm 3.3$ & $38.3 \pm 3.3$ & $39.7 \pm 2.7$ & $>0.05$ \\
Weight (Kg) & $58.1 \pm 0.8$ & $56.6 \pm 0.9$ & $57.5 \pm 0.8$ & $59.6 \pm 0.8$ & $>0.05$ \\
Height (cm) & $156.4 \pm 7.8$ & $158.0 \pm 6.9$ & $159.0 \pm 7.5$ & $155.5 \pm 6.6$ & $>0.05$ \\
BMI & $22.3 \pm 2.1$ & $22.5 \pm 2.1$ & $23.1 \pm 2.2$ & $23.4 \pm 2.3$ & $>0.05$ \\
Male & 14 & 10 & 11 & 13 & 12 \\
Female & 11 & 15 & 14 & & \\
\hline
\end{tabular}

Table II

Different parameters of the patient at the beginning of the study

\begin{tabular}{lccccc}
\hline & $\begin{array}{c}\text { Group I } \\
\text { Mean } \pm \text { SE }\end{array}$ & $\begin{array}{c}\text { Group II } \\
\text { Mean } \pm \text { SE }\end{array}$ & Mean \pm SE & Mean \pm SE & P value \\
\hline Systolic BP mmHg & $129.2 \pm 7.5$ & $128.0 \pm 5.6$ & $129.8 \pm 6.9$ & $127.2 \pm 5.1$ & $>0.05$ \\
Diastolic BP mmHg & $76.1 \pm 2.6$ & $74.8 \pm 2.7$ & $75.6 \pm 2.1$ & $77.2 \pm 2.0$ & $>0.05$ \\
R/R per min & $16.5 \pm 0.4$ & $15.8 \pm 0.4$ & $16.7 \pm 0.2$ & $17.2 \pm 0.3$ & $>0.05$ \\
\hline
\end{tabular}

Group I: Bupivacaine and Ketorolac; Group II: Ketorolac I/V; Group III: Bupivacaine infiltrate Group IV: Control; P value reached from ANOVA test.

All pre operative parameters between different groups at arrival were not statistically significant $(P>0.05)$ in ANOVA test.

Table III

Effect of different pre-emptive medication on systolic blood pressure

\begin{tabular}{lccccc}
\hline & $\begin{array}{c}\text { Group I } \\
\text { (Mean } \pm \text { SE) }\end{array}$ & $\begin{array}{c}\text { Group II } \\
\text { (Mean } \pm \text { SE) }\end{array}$ & Group III & Group IV & P value \\
\hline After 2 hours & $122.0 \pm 7.2$ & $123.4 \pm 4.7$ & $120.4 \pm 7.1$ & $132.4 \pm 2.9$ & $<0.05$ \\
After 4 hours & $123.0 \pm 4.5$ & $122.2 \pm 3.1$ & $122.0 \pm 5.2$ & $129.4 \pm 5.7$ & $>0.05$ \\
After 12 hours & $122.6 \pm 8.2$ & $124.4 \pm 5.2$ & $123.1 \pm 6.4$ & $126.4 \pm 4.6$ & $>0.05$ \\
After 24 hours & $121.5 \pm 6.3$ & $123.4 \pm 8.3$ & $124.5 \pm 6.8$ & $129.4 \pm 3.7$ & $>0.05$ \\
\hline
\end{tabular}


Table III

Effect of different pre-emptive medication on diastolic blood pressure

\begin{tabular}{lccccc}
\hline & $\begin{array}{c}\text { Group I } \\
(\text { Mean } \pm \text { SE) }\end{array}$ & $\begin{array}{c}\text { Group II } \\
(\text { Mean } \pm \text { SE) }\end{array}$ & $\begin{array}{c}\text { Group III } \\
(\text { Mean } \pm \text { SE) }\end{array}$ & $\begin{array}{c}\text { Group IV } \\
(\text { Mean } \pm \text { SE) }\end{array}$ & P value \\
\hline After 2 hours & $78.0 \pm 3.5$ & $74.4 \pm 2.1$ & $79.2 \pm 1.9$ & $84.5 \pm 1.3$ & $>0.05$ \\
After 4 hours & $77.0 \pm 4.5$ & $76.4 \pm 4.3$ & $78.2 \pm 2.7$ & $75.4 \pm 3.1$ & $>0.05$ \\
After 12 hours & $79.0 \pm 3.1$ & $77.4 \pm 3.6$ & $79.8 \pm 3.6$ & $73.2 \pm 4.3$ & $>0.05$ \\
After 24 hours & $78.6 \pm 5.2$ & $75.8 \pm 5.7$ & $74.2 \pm 4.1$ & $78.0 \pm 3.2$ & $>0.05$ \\
\hline
\end{tabular}

Table III

Effect of different pre-emptive medication on respiratory rate

\begin{tabular}{lccccc}
\hline & $\begin{array}{c}\text { Group I } \\
(\text { Mean } \pm \text { SE) }\end{array}$ & $\begin{array}{c}\text { Group II } \\
(\text { Mean } \pm \text { SE) }\end{array}$ & $\begin{array}{c}\text { Group III } \\
(\text { Mean } \pm \text { SE) }\end{array}$ & $\begin{array}{c}\text { Group IV } \\
(\text { Mean } \pm \text { SE) }\end{array}$ & P value \\
\hline After 2 hours & $16.3 \pm 0.3$ & $15.9 \pm 0.3$ & $16.2 \pm 0.3$ & $15.5 \pm 0.3$ & $<0.05$ \\
After 4 hours & $15.9 \pm 0.1$ & $15.8 \pm 0.2$ & $17.1 \pm 0.2$ & $16.0 \pm 0.3$ & $>0.05$ \\
After 12 hours & $16.1 \pm 0.1$ & $16.2 \pm 0.2$ & $17.0 \pm 0.2$ & $16.2 \pm 0.2$ & $>0.05$ \\
After 24 hours & $16.3 \pm 0.2$ & $16.2 \pm 0.2$ & $16.6 \pm 0.2$ & $16.0 \pm 0.2$ & $>0.05$ \\
\hline
\end{tabular}

Table IV

Effect of different pre-emptive medication on sedation score

\begin{tabular}{lccccc}
\hline & $\begin{array}{c}\text { Group I } \\
\text { (Mean } \pm \text { SE) }\end{array}$ & $\begin{array}{c}\text { Group II } \\
(\text { Mean } \pm \text { SE) }\end{array}$ & $\begin{array}{c}\text { Group III } \\
(\text { Mean } \pm \text { SE) }\end{array}$ & $\begin{array}{c}\text { Group IV } \\
\text { (Mean } \pm \text { SE) }\end{array}$ & P value \\
\hline After 2 hours & $2.4 \pm 0.2$ & $2.3 \pm 0.1$ & $2.2 \pm 0.1$ & $2.7 \pm 0.1$ & $<0.05$ \\
After 4 hours & $1.8 \pm 0.2$ & $1.9 \pm 0.1$ & $2.0 \pm 0.2$ & $3.0 \pm 0.1$ & $<0.05$ \\
After 12 hours & $1.7 \pm 0.2$ & $1.2 \pm 0.1$ & $1.6 \pm 0.1$ & $2.8 \pm 0.2$ & $<0.05$ \\
After 24 hours & $1.0 \pm 0.2$ & $1.1 \pm 0.2$ & $1.2 \pm 0.1$ & $2.4 \pm 0.1$ & $<0.05$ \\
\hline
\end{tabular}

Sedation Score

Awake \& alert: 1; $\quad$ Awake \& drowsy: 2;Asleep \& readily arousable: 3;Asleep: 4

Table V

Effect of different pre-emptive medication on vocal response score

\begin{tabular}{lccccc}
\hline & $\begin{array}{c}\text { Group I } \\
\text { (Mean } \pm \text { SE) }\end{array}$ & $\begin{array}{c}\text { Group II } \\
\text { (Mean } \pm \text { SE) }\end{array}$ & $\begin{array}{c}\text { Group III } \\
(\text { Mean } \pm \text { SE) }\end{array}$ & $\begin{array}{c}\text { Group IV } \\
\text { (Mean } \pm \text { SE) }\end{array}$ & P value \\
\hline After 2 hours & $1.4 \pm 0.2$ & $1.5 \pm 0.1$ & $1.6 \pm 0.1$ & $2.6 \pm 0.2$ & $>0.05$ \\
After 4 hours & $0.9 \pm 0.1$ & $1.3 \pm 0.1$ & $1.4 \pm 0.2$ & $2.8 \pm 0.1$ & $>0.05$ \\
After 12 hours & $0.8 \pm 0.2$ & $1.2 \pm 0.0$ & $1.3 \pm 0.2$ & $2.1 \pm 0.2$ & $>0.05$ \\
After 24 hours & $0.4 \pm 0.1$ & $0.8 \pm 0.1$ & $0.9 \pm 0.2$ & $1.6 \pm 0.2$ & $>0.05$ \\
\hline
\end{tabular}

Verbal Rating Score

No pain: 0; $\quad$ Mild Pain: 1; $\quad$ Moderate Pain: 2; $\quad$ Severe Pain: 3 
Table VI

Pethidine consumption

\begin{tabular}{lc}
\hline Group & Pethidine Consumption \\
\hline Group I & $0.1 \pm 0.1 \mathrm{ml}$ \\
Group II & $0.9 \pm 0.1 \mathrm{ml}$ \\
Group III & $1.1 \pm 0.2 \mathrm{ml}$ \\
Group IV & $2.7 \pm 0.1 \mathrm{ml}$ \\
\hline
\end{tabular}

Table VII

Adverse effects of the patient

\begin{tabular}{ll}
\hline Group & Adverse effects \\
\hline Group I & No adverse effects \\
Group II & Nausea \\
Group III & Nausea, vomiting, GI \\
Group IV & Nausea, vomiting \\
\hline
\end{tabular}

Table VIII

Patient satisfaction

\begin{tabular}{ll}
\hline Group & Satisfaction level \\
\hline Group I & Highly satisfied \\
Group II & Satisfied \\
Group III & Average \\
Group IV & Not satisfied \\
\hline
\end{tabular}

\section{DISCUSSION}

The result of present study showed better analgesic effect with combination of I/V Ketorolac and Bupivacaine pre-emptive infiltration measured by PCA based small intermittent dose of intravenous Pethidine. The PCA administration is considered to be safe, as there was no serious outcome seen by using small intermittent administration of Pethidine, such as respiratory depression or severe hypoxemia which is common to all usual dose of Pethidine.

The similar analgesic effect was also obtained using other combination such as Morphine with Indomethacin, Morphine with Ketorolac and Fentanyl with Diclofenac etc. However, in those combined studies, routes of drugs administration were different $12,22-25$. In most of such studies opioids were administered by PCA and NSAIDs by intra-muscularly or intravenously or a suppository forms. In 1996, another study showed that the post operative pain score had decreased during the first 2 hour and had reached a lower level by 4 hours with their combined analgesic study with PCA opioid administration. This study was based on used Alfentanil as an opioid and piroxicam as an NSAIDs which were administrated postoperatively ${ }^{28}$

Endocrine response to surgery and pain always associated with alteration in blood pressure, respiratory rate. Present study showed that mean value of systemic blood pressure and respiratory rate at arrival were not different.

Whereas, other studies did not show any significant change in life threatening respiratory problem associated with the use of $\mathrm{PCA}^{29,30,31}$. These events were almost always associated with human error, usually related to pump programming. Major factor limiting the use of PCA other than side effects was patient factors and cost effectiveness ${ }^{32,33}$. Present combined technique with small intermittent intravenous dose of Pethidine provides excellent level of post-operative analgesia without respiratory depression or severe hypoxeamia. This pain relief technique found to be safe and cost effective compared to PCA based combined analgesia. PCA therapy provides improved analgesia compared with 'as needed intramuscular' opioid administration in-patients undergoing a variety of surgical procedures ${ }^{34-36}$.

The mean sedation score of post operative period after 24 hours in group I was $0.4+0.2$, group II was $0.0+0.0$, group III was $0.4 \pm 0.1$ and group IV was $1.0 \pm 0.1$. The mean different of sedation score of post operative period after 24 hours in group I Vs group II, group I Vs group IV, group II Vs group III and group III Vs group IV was statistically significant $(p<0.05)$ in unpaired test others were not statistically significant.

The combinations of pre-emptive analgesia reduce the requirement of Pethidine and also reduce post operative nausea and vomiting. There was no NSAID related side effect was observed in present study. This finding was supported by the findings of an other studies $^{37}$. Reduced dose of combined pre emptive analgesia was due to opoid sparing effect of NSAID and by synergistic effects in intravenous Ketorolac. These findings were supported by stable haemodynamic status. Well controlled post operative pain associated with reduced sympathetic activity thus prevents or minimizes the stress response which is desirable for a surgical patient. Pre-emptive therapy thus showed to have better management procedure in reducing post operative pain and post operative Pethidine requirement.

This study was an attempt to find out the efficacy of pre-emptive analgesia in reducing post-operative pain. Multiple pre-emptive therapies were used in an attempt to see its superiority over single pre-emption. Pain scores showed significant differences between the pre-emptive and non pre-emptive groups. Pethidine consumed by the pre-emptive non-recipient group was much higher. 
Patient's satisfaction was higher and post operative complications were less in the pre-emptive recipient group. Thus pre-emptive multimodal therapy would be better, in reducing post-operative pain, and the amount of post-operative analgesic requirement. It might be concluded that multimodal pre-emptive therapy by using I/V Ketorolac \& Bupivacaine infiltration is an effective method for post operative pain management in maxillofacial surgery.

\section{REFERENCES:}

1. Edward AT, Whitaker D, Browne K, Pooley FD, Gibbs AR. Mesothelioma in a community in the north of England. Occup Environ Med. 1996; 53: 547-52.

2. Jaeger A, Flesch F, Kopferschmitt J, Sauder P. Acute paracetamol poisoning. Rev Prat. 1987; 37: 2881-6.

3. Kehlet $\mathrm{H}$. The endocrine responses to regional anesthesia. Int Anesthesiol Clin. 1988; 26:182-6.

4. Scott NB, Kehlet $\mathrm{H}$. Regional anaesthesia and surgical morbidity. Br J Surg. 1988; 75: 299-304.

5. Cousins FW. Chapter and Verse. Nature. 1989; 341: 380.

6. Desborough JP. The stress response to trauma and surgery. Br J Anaesth. 2000; 85: 109-17.

7. Brandt MR, Korshin J, Hansen AP, Hummer L, Madsen SN, Rygg I, Kehlet $\mathrm{H}$. Influence of morphine anaesthesia on the endocrine-metabolic response to open-heart surgery. Acta Anaesthesiol Scand. 1978; 22:400-12.

8. Modig J, Borg T, Bagge L, Saldeen T. Role of extradural and general anesthesia in fibrinolysis and coagulation after total hip replacement. Br J Anaesth 1983; 55: 625-9

9. Desborough JP, Edlin SA, Burrin JM, Bloom SR, Morgan M, Hall GM. Hormonal and metabolic responses to cholecystectomy: comparison of extradural somatostatin and diamorphine. $\mathrm{Br} \mathrm{J}$ Anaesth 1989; 63: 508-15.

10. Bromage PR, Shibata HR, Willoughby HW. Influence of prolonged epidural blockade on blood sugar and cortisol responses to operations upon the upper part of the abdomen and the thorax. Surg Gynecol Obst. 1971; 132: 1051-6.

11. AHCPR. Acute pain management operative or medical procedure and trauma: Clinical practice guidelines 1992 AHCPR pub No. 92 - 0032.

12. Van Lancker P, Devulder J, Rolly G. Systemic piroxicam as an adjunct to patient controlled analgesia with alfentanil for postoperative pain relief. Anaesthesia 1996; 51: 65862.

13. Kenny GN, White M. A portable computerized infusion system for Propofol. Anaesthesia 1990; 45: 692-3.

14. Grass JA, Sakima NT, Valley M, Fischer K, Jackson C, Walsh P, Bourke DL. Assessment of ketorolac as an adjuvant to fentanyl patient-controlled epidural analgesia after radical retropubic prostatectomy. Anesthesiology. 1993; 78: 642-8.
15. Cardoso MM, Carvalho JC, Amaro AR, Prado AA, Cappelli EL. Small doses of intrathecal morphine combined with systemic diclofenac for postoperative pain control after cesarean delivery. Anesth Analg. 1998; 86: 538-41.

16. Joyce CR, Zutshi DW, Hrubes V, Mason RM. Comparison of fixed interval and visual analogue scales for rating chronic pain. Eur J Clin Pharmacol. 1975; 8: 415-20.

17. Sriwatanakul K, Kelvie W et al. Studies with different types of visual analogue scales for measurement of pain. Clin Pharm Ther 1983; 34: 234-9.

18. Huskisson EC. Measurement of pain. J Rheumatol. 1982; 9: $768-9$

19. Van Buren J, Kleinknecht RA. An evaluation of the McGill pain questionnaire for use in dental pain assessment. Pain 1979; 6: 23-33.

20. Melzack R, Taenzer $\mathbf{P}$ et al. Labour is still painful after prepared Childbirth training. CMAJ 1981; 125:357-63.

21. Katz J, Melzack R. Auricular TENS reduces phantom limb pain and Symptom management 1991, 6: 73-83.

22. Burns JW, Aitken HA et al. Double blind comparison of the morphine sparing effect of continuous and intermittent I.M administered of ketorolac. Br. J. Anaesth. 1991; 67: 2358.

23. Laitinen JL, Nuutinen L. Intravenous diclofenac coupled with PCA fentanyl for pain relief after total hip replacement. Anesthesiology 1992; 76: 194-8.

24. Murphy DF, Medley C. Preoperative indomethacin for pain relief after thoracotomy Comparison with postoperative indomethacin. Br. J. Anaesth. 1993; 70: 298-300.

25. Cataldo PA, Senagore AJ, Kilbridge MJ. Ketorolac and patient controlled analgesia in the treatment of post operative pain. Surg Gyenocol Obster 1993; 176: 435-8.

26. Dahl JB, Kehlet $\mathrm{H}$. Non-steroidal anti-inflammatory drugs: rationale for use in severe postoperative pain. $\mathrm{Br} \mathrm{J}$ Anaesth. 1991; 66: 703-12.

27. Tverskoy M, Cozacov C, Ayache M, Bradley EL Jr, Kissin I. Postoperative pain after inguinal harniorrhaphy with different anesthesia. Anesth Analg. 1990; 70: 29-35.

28. Lancker PV et al. Systemic piroxicam as an adjunct to patient-controlled analgesia with alfentanil for postoperative pain relief. Anaesthesia 1996; 51:658-62.

29. Thomas DW, Owen H. Patient-controlled analgesis: the need for caution. A case report and review of adverse incidents. 1998; 75:177-85.

30. White PF: Mishaps with patinet-controlled analgesia. Anesthesiology 1987; 66: 81-3.

31. Ashburn MA, Love G, Pace NL. Respiratory-related critical events with intravenous patient control anesthesia. Clin J Pain. 1994 ; 10: 52-6.

32. Thomas T, Robinson C, Champion D, McKell M, Pell M. Prediction and assessment of the severity of postoperative

January / July 2008 
pain and of satisfaction with management. Pain. 1998; 75 : 177-85.

33. Ferrante FM, Kaufman AG, Dunbar SA, Cain CF, Cherukuri $\mathrm{S}$. Sphenopalatine ganglion block for the treatment of myofacial pain of the head, neck and shoulder. Reg Anesth Pain Med. 1998; 23: 30-6.

34. Eisenach JC, Grice SC, Dewan DM. Patient-controlled analgesia following cesarean section: a comparison with epidural and intramuscular narcotics. Anesthesiology 1988; 68: 444-8.
35. Bollish SJ, Collins CL, Kirking DM, Bertlett RH. Efficacy of patient-controlled versus conventional anesthesia in postoperative pain. Clin Pharma 1985; 4: 48-52.

36. Webb CJ, Stergios DA, Rodgers BM. Patient controlled analgesia as postoperative pain treatment in children. $\mathrm{J}$ Pediatr Nurs. 1989; 4: 162-71.

37. Murphy DF. NSAIDs and postoperative pain. BMJ. 1993; 306: 1493-4. 